\section{Estudo \\ CoDebate}

em Testão

Planejamento
Revista Estudo \& Debate, Lajeado, v. 26, n. 2, 2019. ISSN 1983-036X

DOI: http://dx.doi.org/10.22410/issn.1983-036X.v26i2a2019.2071

\title{
AMBIENTES DE APRENDIZAGEM: ESTUDO DA APLICAÇÃO DE JOGOS DE EMPRESAS NAS IES DOS CURSOS DE CIÊNCIAS CONTÁBEIS DO ESTADO DE MATO GROSSO
}

\author{
Paloma Busanello Corrêa ${ }^{1}$, Sofia Ines Niveiros ${ }^{2}$, João Bosco Arbués Carneiro Júnior ${ }^{3}$
}

\begin{abstract}
Resumo: A presente pesquisa tem o objetivo de analisar a contribuição dos Jogos de Empresas, quando utilizados no ambiente educacional, como metodologia de ensino-aprendizagem nas matrizes curriculares dos cursos de graduação de Ciências Contábeis no Estado de Mato Grosso. Em relação à metodologia de pesquisa, este trabalho se enquadra como Descritiva, Levantamento, a partir de uma abordagem qualitativa do problema. Para coletar os dados, utilizaram-se dois questionários que foram encaminhados via e-mail para as IES. Os resultados obtidos demonstram que de dez Instituiçóes que responderam os questionários, somente uma faz o uso da ferramenta na matriz curricular do curso, sendo que para esta IES, tal metodologia tem contribuído de forma satisfatória para o desempenho dos discentes. Identificou-se que esta ferramenta permitiria que os acadêmicos vivenciassem o mundo real, através de simulaçóes empresariais virtualmente. Sugere-se que em função dos benefícios que esta ferramenta proporciona aos discentes e ao processo ensino-aprendizagem outras IES do Estado de Mato Grosso utilizem este método de ensino, ou seja, acrescentem Jogos de Empresas em suas matrizes curriculares.
\end{abstract}

Palavras-chave: Jogos de Empresas. Ensino-aprendizagem. Ambiente Educacional.

\section{LEARNING ENVIRONMENTS: STUDY OF THE APPLICATION OF COMPANY GAMES IN THE HEADS OF COURSES OF ACCOUNTING SCIENCES OF THE STATE OF MATO GROSSO}

\begin{abstract}
The present research has the objective of analyzing the contribution of Business Games, when used in the educational environment, as teaching-learning methodology in the curricular matrices of the undergraduate courses in Accounting Sciences in the State of Mato Grosso. In relation to the research methodology, this work is classified as Descriptive, Survey, from a qualitative approach of the problem. To collect the data, two
\end{abstract}

1 Graduação em Ciências Contábeis pela UFMT. Atualmente atua na empresa Liderança Escritório Contábil no departamento pessoal.

2 Graduação em Ciências Contábeis pela UFSC. Mestre e Doutora em Engenharia de Produção pela UFSC. Docente da Universidade Federal de Mato Grosso/CIC/ICHS/CUR.

3 Graduação em Ciências Contábeis pela UFMT. Mestrado em Ciências Contábeis pela UFRJ. Doutorando em Meio Ambiente e Desenvolvimento Regional (UNIDERP). 
questionnaires were used and sent to the IES by e-mail. The results obtained demonstrate that of ten institutions that answered the questionnaires, only one makes use of the tool in the curricular matrix of the course, and for this IES, such methodology has contributed in a satisfactory way to the performance of the students. It was identified that this tool would allow academics to experience the real world, through virtual business simulations. It is suggested that due to the benefits that this tool provides to students and to the teachinglearning process other IES in the State of Mato Grosso use this teaching method, that is, they add Business Games in their curricular matrices.

Keyword: Business Games. Teaching-learning. Educational Environment.

\section{INTRODUÇÁO}

As transformaçóes da sociedade acontecem diariamente, nos diversos campos do saber, tais como cultural, econômico, social e, inclusive, no educacional, exigindo novos saberes e novas competências, a fim de alcançar maior velocidade e agilidade na tomada de decisōes. Deste modo, um dos maiores desafios enfrentados atualmente por Instituiçóes de Ensino Superior (IES) é a transformação e reconstituição do saber, uma vez que buscam constantemente aperfeiçoar a concepção de mundo, sociedade e homem.

A educação brasileira tem passado por modificaçôes na prática pedagógica tendo como intuito construir e gerenciar novas didáticas educacionais. (GUBERT, MACHADO, 2008). O foco da transformação é conhecer os novos significados dos indivíduos e culturas, traçando sua própria história na sociedade e exige que os currículos das IES estejam em consonância com os interesses do mercado.

Bueno et al (2004) descrevem a importância do currículo e da didática trabalharem em ambientes colaborativos considerando princípios tais como aprendizagem contínua, colaborativa e participativa; relacionar o conhecimento ao contexto; reflexão individual e coletiva em situações práticas; elaboração de projetos de trabalho coletivo através de pesquisa-ação. Para tanto é necessária uma reengenharia educacional, cuja mudança deve ser realizada em três bases: (a) em relação à dinâmica em sala de aula, (b) à didática do docente e (c) principalmente a postura do discente de uma participaçáo passiva para uma ativa.

Para facilitar a aprendizagem dos discentes, considera-se que o seu desenvolvimento e seu desempenho sejam diferentes do outro, pois não há homogeneidade no processo de aprendizagem (MARION; MARION, 2006). Assim, o ideal é que o docente utilize ferramentas ou técnicas que atendam aos objetivos de todos, sendo o principal responsável pelo sucesso dos discentes no processo educacional.

A classe contábil não está excluída desse processo de transformação e o mercado de trabalho procura o profissional preparado para enfrentar essas mudanças. As universidades têm como função levar a Ciência Contábil ao atendimento das expectativas dos usuários. Nesse sentido, Parisotto, Grande e Fernandes (2006, p. 2) afirmam que "[...] é necessário que o ensino da contabilidade evolua, com vistas à formação de profissionais competentes e ao desenvolvimento desta ciência". A evolução do ensino deve ser facilitada pela metodologia dos docentes. De acordo com Marion, Garcia e Cordeiro (2006, p. 3), "[...] o professor deve ser um verdadeiro estrategista [...] no sentido de estudar, selecionar, organizar e propor as melhores ferramentas facilitadoras para que os estudantes se apropriem do conhecimento". 
Lopes et al (2013) concluíram que as atividades vivenciais podem contribuir para acelerar o processo de formação, na medida em que possibilitam aos indivíduos experimentar, avaliar, refletir e agir, em ambientes seguros e próximos à realidade.

Os principais métodos de ensino são: aula expositiva, jogos de empresas, seminário, discussóes com toda a classe, discussōes com pequenos grupos e estudo de caso. Dentre eles, neste trabalho, enfatizam-se os Jogos de Empresas, que de acordo com Parisotto, Grande e Fernandes (2006, p. 7) "[...] baseia-se nos mesmos moldes do estudo de caso, porém destaca-se o implemento das tecnologias de ensino, com o uso de computadores e acesso à internet". Marion, Garcia e Cordeiro (2006, p. 3) complementam: "Permite ao aluno, em grupo, tomar decisóes em empresas virtuais, negociando com outras empresas de outros grupos da sala de aula ou até mesmo de outras classes, períodos e cursos".

Nesta abordagem, pode-se dizer que o ensino e a aprendizagem são uma relaçáo recíproca, pois aquilo que o professor ensina o aluno aprende. Sendo assim, destacase o papel dirigente do docente e a atividade do discente. O ideal é que o processo de aprendizagem não seja passivo, ou seja, o método tradicional de ensino trazia os docentes transferindo conhecimentos, mas os discentes náo se envolviam com tanta motivaçáo. Esta nova metodologia ativa, conduz com dinamicidade a aprendizagem. A proposta é ter estudantes pensadores-críticos, com posturas dinâmicas de estudos, estimulados aos questionamentos e especialmente nas tomadas de decisóes com iniciativa.

Um dos métodos de ensino alternativo que será abordado mais detalhadamente são os Jogos de Empresas. Esta ferramenta aplica na prática todo o conteúdo teórico apresentado em sala de aula, transmitindo assim a responsabilidade em saber como tomar decisóes em tempos reais, ou seja, simulam-se as vivências na aprendizagem ativa. Para Santos (2003, p. 78) "Um jogo de empresas permite, em laboratório, experimentos muitas vezes não possíveis na realidade, propiciando aos jogadores novas experiências, sendo um recurso adicional para fixação do aprendizado, simulando situações reais de gestão e/ou outras".

Os jogos de simulação empresarial surgiram no Brasil na década de 60, com o intuito de aperfeiçoar os recursos de ensino-aprendizagem (YOUSSEF; RAMIREZ, 2011). Além disso, este método auxilia no entendimento dos discentes para tomarem decisóes em suas empresas virtuais, sendo competitivas no mercado, estimulando a criatividade empresarial e o trabalho em equipe.

Diante do exposto, este trabalho tem como foco responder a seguinte questão: Como a utilizaçáo dos Jogos de Empresas, no ambiente educacional dos cursos de graduaçáo de Ciências Contábeis do Estado de Mato Grosso, pode favorecer o processo de ensino e de aprendizagem? Desta forma, o estudo objetiva analisar a contribuiçáo dos Jogos de Empresas, quando utilizados no ambiente educacional, como metodologia no processo de ensino e de aprendizagem nas matrizes curriculares dos cursos de graduação de Ciências Contábeis no Estado de Mato Grosso. Para atingir este objetivo foram seguidas as seguintes etapas: (a) diagnosticar quais IES do Estado de Mato Grosso que possuem o curso de Ciências Contábeis oferecem Jogos de Empresas nas suas matrizes curriculares; (b) investigar, juntamente com os coordenadores das IES, o motivo da não utilização desta ferramenta, caso não a utilizem; (c) destacar as vantagens do uso dos Jogos de Empresas como ferramenta no processo de ensino e de aprendizagem junto aos coordenadores das 
IES que a possuem em sua matriz curricular; e (d) identificar o perfil dos docentes que ministram aulas com esta ferramenta.

Os Jogos Simulados trazem para as universidades as vantagens de aprendizagem participativa, desenvolvimento de habilidades gerenciais, além de permitir observar atitudes empreendedoras em coordenadores, professores e acadêmicos (SAUAIA, 2006). É relevante o estudo deste método, pois por meio dele é possível conciliar a aprendizagem com a satisfação e a dinamicidade.

Este processo educacional pode desempenhar um importante papel nos cursos de Ciências Contábeis, já que a ferramenta auxilia na junção de operacionalizar a teoria aplicada em sala com a prática de um jogo simulado, oferecendo a oportunidade de vivenciar uma experiência virtual com base na realidade. Disponibilizar esta metodologia aos discentes do curso de Ciências Contábeis é um mecanismo que possibilita prepará-los para o mercado de trabalho com maior eficiência e, sobretudo, a desenvolverem com maior facilidade as obrigaçóes como profissional contábil.

\section{FUNDAMENTAÇÃO TEÓRICA}

Este tópico inicia descrevendo como surgiram os Jogos de Empresas e sua definição, os métodos de ensino, a tecnologia como ferramenta atual e a importância dos Jogos de Empresas nas matrizes curriculares dos cursos de Ciências Contábeis.

\subsection{Origem dos Jogos de Empresas}

Desde a pré-história os jogos acompanham a humanidade. Alguns autores pesquisados relatam que as simulaçóes eram realizadas no Egito antigo. Em escavações efetivadas na Mesopotâmia, regiāo da antiga cidade Suméria de Ur, foi encontrado um jogo de tabuleiro denominado Jogo Real de Ur com mais de 5.000 anos de idade. (YOUSSEF; RAMIREZ, 2011). Por isso, ressalta-se que antes de existir os jogos empresariais ou simuladores eletrônicos houve os jogos manuais, ou seja, planejavam, estruturavam para projetarem as decisões a serem tomadas em tabuleiros, a punho. O termo Jogos de Empresas tem origem no termo inglês Business Game. A tradução para o português traz uma conotação lúdica para a atividade. (ALMEIDA, 1998).

Os primeiros relatos sobre a utilização dos jogos na educação e no desenvolvimento das habilidades teriam ocorrido, na China, com os "Jogos de Guerra" por volta de 3.000 anos A.C. com a simulação da guerra Wei-Hai e na Índia com o jogo Chaturanga. O jogo New Kriegspiel criado por George Venturini, em Schleswig, em 1798 é o mais elaborado dentre os já citados. Os simuladores denominados "Jogos de Guerra” através da evolução passaram a ser chamados "Jogos Empresariais". Em 1957, surgiu nos Estados Unidos, o primeiro jogo voltado para o público acadêmico elaborado por Schreiber na Universidade de Washington, nomeado Top Management Decision Simulation, desenvolvido pelos pesquisadores da American Management Association. A filosofia deste procedimento foi adaptada do jogo de guerra para o âmbito de negócios (KEYS; WOLFE, 1990, p. 309).

$\mathrm{Na}$ segunda guerra mundial, ocorreram alguns fatos que tiveram como utilidade os simuladores. Um deles foi o treinamento dos pilotos para a $2^{\circ}$ guerra, pois com este recurso 
os oficiais podiam pilotar e aprender a fazer manobras sem causar nenhum dano ou sofrer algum risco de vida (SAUAIA, 1995). Outro fato foi durante as invasóes da França pelos alemães e de Pearl Harbor pelos japoneses em que as ações foram direcionadas com o auxílio de simulaçóes (YOUSSEF; RAMIREZ, 2011).

As Simulaçōes Empresariais, em meados dos anos 1950, começaram a ganhar maior credibilidade e importância na sociedade. Com isso, na década de 1960, os Jogos de Empresas computadorizados alavancaram e resultaram em mais de 100 jogos desenvolvidos para o meio acadêmico. Este crescimento tem sido constante, em 1980 já eram utilizados mais de 1.500 jogos empresariais com o objetivo de auxiliar em treinamentos nas universidades e empresas (SAUAIA, 1995).

No Brasil, os Jogos de Empresas tiveram início na década de 1960, sendo implantados em algumas universidades, nas grades curriculares. Com o passar dos anos, obteve-se maior estabilidade na execução desta ferramenta de ensino, devido à ampla difusão dos computadores e a possibilidade de gerar os jogos via internet. A princípio os jogos foram importados e traduzidos. Atualmente, existem equipes de pesquisadores brasileiros que desenvolvem simuladores com o intuito de alcançar as necessidades solicitadas pelo mercado empresarial nacional (YOUSSEF; RAMIREZ, 2011).

\subsection{Definiçáo dos Jogos de Empresas}

Os Jogos de Empresas têm ganhado espaço no cenário empresarial e educacional. Para promover conhecimentos, espera-se que esta ferramenta impulsione o discente a deixar de ser agente passivo, apenas receptor de informaçóes, para passar a ser agente ativo, que transmite e recebe conhecimentos em ambos os momentos, tornando o ensino com um maior aproveitamento.

A seguir seguem definiçóes de pesquisas em épocas diferentes, a fim de verificar quais são os conceitos de alguns autores sobre Jogos de Empresas.

Para Santos (2003, p. 83) Jogos de Empresas podem ser definidos como: “[...] abstraçóes matemáticas simplificadas de uma situaçáo relacionada com o mundo dos negócios. Os participantes do jogo, individualmente ou em equipes, administram a empresa como um todo ou parte dela, através de decisões sequenciais". Nesta afirmação, entendese o Jogo de Empresa como um modelo virtual que utiliza um cenário real elaborado com o objetivo de desenvolver e aprimorar as habilidades existentes em cada participante ou discente. Com isso, propicia-se um aprendizado flexível, dinâmico e prático mesmo diante dos principais desafios da organizaçáo empresarial.

Segundo Sauaia (2006), os Jogos de Empresas representam um método educacional que proveem uma dinâmica vivencial similar à realidade de uma empresa. $\mathrm{O}$ aluno projeta os seus conhecimentos teóricos adquiridos na simulação, na medida em que identifica e mapeia pontos fortes e fracos na empresa virtual, interage com os seus colegas e toma decisões.

Esta ferramenta é utilizada no meio acadêmico com o intuito de proporcionar aos discentes uma experiência prática de negócios e gestáo empresarial. Os acadêmicos assumem papéis fundamentais de gerenciar e programar metas organizacionais. Tomando decisóes 
com base em sistemas de apoio ou softwares desenvolvidos para esta ação, os mesmos desenvolvem habilidades em administração de empresas.

Laffin (2002, p. 136) descreve sobre a característica dos jogos: "A importância de se usar exemplos e problemas reais, estimulando a busca de soluçóes e a capacidade de organizar e de apresentar as próprias ideias de forma convincente é reconhecida por todos". Neste meio virtual as tomadas de decisóes são incertas, pois se associam aos conhecimentos obtidos em sala de aula, cooperam, planejam, estabelecem estratégias e competem, realizam metas e objetivos, assim busca prepará-los para aproveitar as oportunidades e enfrentar as ameaças.

As definições apresentadas se complementam e têm a mesma visão, ou seja, os Jogos de Empresas são simuladores empresariais, que tem como foco oferecer experiências práticas aos discentes.

Desta forma, neste trabalho entendem-se Jogos de Empresas como método de ensino, o qual agrega ao conteúdo programático das aulas teóricas, dando a oportunidade aos discentes ou participantes terem como base empresarial uma experiência virtual com direito a tomada de decisóes e situaçóes similares ao da vida real nas mais diversas empresas existentes. Ainda neste trabalho, visa-se retratar como os Jogos de Empresas podem colaborar para o processo de ensino e de aprendizagem nos cursos pertinentes ao desenvolvimento empresarial.

\subsection{Métodos de ensino}

É de suma importância a escolha de um método de ensino adequado para o sucesso do aprendizado. Segundo Marion e Marion (2006), alguns dos métodos ou instrumentos de ensino apropriados para a área de negócios, são: a) Aula Expositiva; b) Exposições e Visitas; c) Dissertação; d) Projeção de fitas; e) Seminário; f) Palestras e Entrevistas; g) Discussão e Debate; h) Resolução de Exercícios; i) Estudos Dirigidos; j) Estudo de Caso; k) Jogos de Empresas; l) Simulaçóes; m) Role-Play - Desempenho de papeis; e n) Outros Métodos ou instrumentos como: Método de Grupo "T" (treinamento de sensibilidade); Internet, Auto Estudo, entre outros.

O fundamental na utilização destes métodos ou instrumentos é buscar aplicar o melhor ajuste à característica do público-alvo e ao objetivo a ser atingido pelo conteúdo a ser ministrado. Ressalta-se que todos os métodos apresentam vantagens e desvantagens em um ou outro momento do processo de ensino e de aprendizagem aplicado na área de negócios.

A necessidade de mudança, entretanto, não é uma demanda provocada exclusivamente pela tecnologia da informação e globalização. Freire (2003, p. 47) já afirmava que "ensinar não é transferir conhecimento, mas criar possibilidades para a sua própria produção ou sua construção". Para superar as dificuldades encontradas no processo de mudanças e para atender o cenário e princípios destacados, sugere-se a implantação da tecnologia em sala de aula por meio da aplicação de jogos educacionais.

Lopes e Wilhelm (2006, p. 7) entendem que por meio dos jogos, o aluno passa a ter um papel "totalmente ativo, pois além de construir o seu conhecimento e buscar exercitar 
conceitos a partir das situaçóes simuladas, ele deve exercitar suas relaçóes e interaçóes sociais tanto com os colegas de seu próprio grupo (essencialmente colaborativos) quanto no trabalho com colegas de outros grupos (que pode ser competitivo ou colaborativo)". Esta ferramenta atende as transformaçóes desejadas para o ambiente educacional. Fazendo um link de ligação entre as teorias adquiridas com os métodos tradicionais de educação e o profissional capacitado desejado atualmente pelo mercado de trabalho. Esta capacitação virtual é um preparo para enfrentar o que pode ocorrer no dia-a-dia deste profissional.

A aprendizagem passiva, ou seja, o método tradicional de ensino onde a transferência de conhecimento ocorre do professor para o discente com pouco envolvimento dos alunos no processo de ensino e de aprendizagem apresenta menos vantagens que a aprendizagem ativa. Esta outra metodologia conduz dinamicidade na aprendizagem.

Rollo e Pereira (2003), entre as características da aprendizagem ativa, enumeram: (a) tem por meta a formação de estudantes pensadores-críticos; (b) possuir maior dinamismo no processo de aprendizagem; (c) estimular o questionamento, a iniciativa, a tomada de decisão; e (d) focar suas atenções no aluno.

Neste contexto pedagógico, os Jogos de Empresas realizados por simulação empresarial oferecem contribuições metodológicas no processo de ensino e de aprendizagem, pois aliam os benefícios da tecnologia com as vivências da aprendizagem ativa.

\subsection{Tecnologia como ferramenta atual}

As práticas pedagógicas do ensino superior estão em fase de transformação. O aprender fazendo, o aprender a aprender, o interesse, a experiência e a participação são desafios cada vez mais importantes para ambos os atores do ensino-aprendizagem (EA): o professor e o aluno (LOBO; MAIA, 2015).

A pedagogia no processo de ensino e de aprendizagem também é um dos alvos afetado pela tecnologia. A mudança quanto a esta didática é permanente, afinal a educação é um ciclo, nunca serão os mesmos discentes e nem docentes; com isso novos desafios existirão, novos métodos deverão ser criados. Com o avanço dos novos tempos, a tecnologia tem sido um ponto forte na metodologia de ensino.

Lobo e Maia (2015) relatam que as novas metodologias são um dos principais desafios do exercício da docência. Zambelo (2011) afirma a mesma ideia quando diz que há abertura para o progresso tecnológico. Porém, é possível haver desmotivação ou incentivos para o uso de novas tecnologias (GIL, 2008; LIMA e SILVA, 2012). Soares, Nogueira e Petarnella (2014) destacam que o meio acadêmico geralmente é positivista e conservador, e isso se encaixa com o perfil do discente atual. Conforme Gracia (2013, pp. 25-26), "com a tecnologia avançando e os novos recursos interativos surgindo, o método tradicional de ensino tem se tornado questionável”. Os docentes, em salas de aula, se deparam com as diferenças nítidas em cada discente e inclusive em seus níveis de conhecimento com relação ao uso da tecnologia.

Por mais que exista o lado negativo da tecnologia de levar conhecimento inadequado para os discentes, há também a visão positiva por ser uma estratégia pedagógica podendo 
ser utilizada pelos docentes, aumentando, assim a eficácia do ensino-aprendizagem. (SCARELLI, 2009; ZAMBELO, 2011; SOARES; NOGUEIRA; PETARNELLA, 2014).

\subsection{A importância dos Jogos de Empresas nas matrizes curriculares dos cursos de Ciências Contábeis}

Para as matrizes curriculares dos cursos de Ciências Contábeis é importante o desenvolvimento dos Jogos de Empresas, pois o discente aprende técnicas e teorias contábeis que são necessárias para o seu desenvolvimento profissional e com isso a prática do ensino ministrado adentra como metodologia de auxílio. Os contadores são formados não somente para realizar registros operacionais, mas para atuarem como gerenciadores de recursos e fornecedores de informaçóes, capazes de auxiliar na tomada de decisóes das organizações, atividades que podem vivenciar na simulação da empresa virtual. Como há muitas incógnitas sobre a prática pós-formação, esta metodologia de ensino transmitida pelos Jogos de Empresas é essencial para dirimir estas dúvidas através do dia a dia de uma empresa, propiciando conhecer detalhadamente todos os procedimentos administrativos, financeiros e econômicos. Simplesmente conhecer técnicas não faz do profissional alguém apto a entrar no mercado. Assim como o médico deve antes de exercer a profissão realizar residência, os contadores deveriam vivenciar uma simulação empresarial com os Jogos de Empresas, para testar as experiências em uma empresa onde as "falhas", o preço e custo destas, seriam uma aprendizagem. Diante desse quadro, os Jogos de Empresas oferecem uma oportunidade de conhecer ferramentas gerenciais e ao mesmo tempo aplicarem os conhecimentos técnicos obtidos em sala de aula, verificando se existe deficiência em sua formação e como poderá corrigir.

$\mathrm{O}$ INEP/MEC divulgam resultados sobre a expansão da educação superior. $\mathrm{O}$ ensino superior brasileiro apresentou, nas últimas décadas, um elevado grau de crescimento no número de matrículas, crescimento de 1.921\% de 1962 a 1997 (KALLAS, 2009. Em 2004, a quantidade de discentes matriculados em IES totalizava 4.163.733. É incontestável que o interesse da sociedade pela educação superior tem aumentado significativamente, seja por universidade pública ou particular. A quantidade de discentes matriculados nos cursos de Ciências Contábeis é também um número relevante. Este dado demonstra as pressóes do mercado competitivo que enfrentam as IES hoje em dia. Um diferencial é oferecer ambiente de ensino com qualidade e preparação para o mercado de trabalho com competitividade. $\mathrm{O}$ ensino deve ser atraente, contextual e formado de coisas úteis e práticas à vida pessoal e profissional. Neste cenário, verifica-se o importante papel da implantação dos Jogos Empresariais.

O Conselho Nacional de Educação, Câmara de Educação Superior na resolução CNE/CES 10, de 16 de dezembro de 2004, instituiu as Diretrizes Curriculares Nacionais para o Curso de Graduação em Ciências Contábeis. Este parecer em seu artigo $5^{\circ}$ determina que os cursos devam contemplar, em seus projetos pedagógicos e em sua organização curricular, conteúdos de formação Teórico-Prática. Refere-se, entre outras atividades, à Prática em Laboratório de Informática utilizando softwares atualizados para Contabilidade. No artigo $4^{\circ}$, especificamente no inciso VII, a referida resolução descreve que "O Curso de Ciências Contábeis deve possibilitar formação profissional que revele, pelo menos, 
as seguintes competências e habilidades: desenvolver, analisar e implantar sistemas de informação contábil e de controle gerencial, revelando capacidade crítico analítica para avaliar as implicaçóes organizacionais com a tecnologia da informaçáo”. Para atender estas prerrogativas do Ministério da Educação, recomenda-se a utilização de Jogos de Empresas.

\section{METODOLOGIA DA PESQUISA}

Esta pesquisa é norteada pelas tipologias preconizadas por Beuren (2010), quanto aos objetivos este trabalho é caracterizado como uma pesquisa descritiva, pois almeja descrever se os Jogos de Empresas estáo sendo utilizados como ferramenta de estudo para dar suporte ao processo de qualidade no ambiente de ensino. Quanto aos procedimentos esta se caracteriza como uma pesquisa de levantamento ou survey. Os dados coletados têm por base a amostra retirada de determinada população ou universo que se deseja conhecer, sendo neste caso IES com cursos de Ciências Contábeis no Estado de Mato Grosso que utilizem a ferramenta Jogos de Empresas. Quanto à abordagem do problema, caracterizase em pesquisa qualitativa, porque tem o foco de analisar como são utilizados os Jogos de Empresas na graduação como processo de qualidade no ambiente de ensino. Esta pesquisa é caracterizada do tipo de plano transversal, já que os dados serão coletados em um período específico do tempo.

A população definida são os cursos de graduação de bacharelado em Ciências Contábeis do Estado de Mato Grosso. Atualmente, há 48 IES no Estado de Mato Grosso. Conforme Marconi e Lakatos (2001, p. 108), a amostra não probabilística não faz o uso de uma forma aleatória de seleção. Seguindo este conceito, o tipo de amostragem desta pesquisa é caracterizado como não probabilístico, já que os critérios de seleção foram estabelecidos de forma racional. Deste modo, foram escolhidas para compor a amostra desta pesquisa as IES que possuem curso presencial.

O Quadro 1 apresenta as IES do Estado de Mato Grosso identificadas por cidade, que são a população da pesquisa. Os dados foram fornecidos pelo Conselho Regional de Contabilidade do Estado de Mato Grosso - CRC/MT (ARRUDA, 2017), os quais foram confrontados com os dados do e-MEC. Estas IES são as que se encontram regularmente em funcionamento, ou seja, em atividade.

Quadro 1 - IES, com curso de Ciências Contábeis no Estado de Mato Grosso

\begin{tabular}{|c|l|c|}
\hline $\mathbf{N}^{\circ}$ & IES - MT & CIDADES \\
\hline 1 & UFMT - Universidade Federal De Mato Grosso & \\
2 & UNIRONDON - Centro Universitário Cândido Rondon & \\
3 & UNIC - Universidade de Cuiabá & CUIABÁ \\
4 & ICE - Instituto Cuiabano de Educação & \\
5 & ICEC - Instituto Cuiabá de Ensino e Cultura integrado com: IES/MT & \\
6 & Faculdade Anhanguera (CPA3) & \\
7 & Faculdade Anhanguera (Fernando Correa) & \multirow{2}{*}{ VÁRZEA GRANDE } \\
\hline 8 & UNIVAG - Universidade de Várzea Grande & \\
9 & UNOPAR VIRTUAL - UNIBED & \\
\hline
\end{tabular}




\begin{tabular}{|c|c|c|}
\hline $\mathbf{N}^{\circ}$ & IES - MT & CIDADES \\
\hline $\begin{array}{l}10 \\
11 \\
12 \\
13 \\
14 \\
15 \\
16 \\
17 \\
18\end{array}$ & $\begin{array}{l}\text { UFMT - Universidade Federal De Mato Grosso } \\
\text { UNIR - Universidade de Rondonópolis } \\
\text { Universidade Metodista de São Paulo } \\
\text { UNOPAR - Universidade Norte do Paraná } \\
\text { UNIP - Universidade Paulista } \\
\text { CESUMAR - Centro Universitário Maringá } \\
\text { Universidade UNIDERP } \\
\text { Universidade Anhanguera } \\
\text { Universidade Claretiano }\end{array}$ & RONDONÓPOLIS \\
\hline $\begin{array}{l}19 \\
20 \\
21\end{array}$ & $\begin{array}{l}\text { UNIVAR - Faculdade Unida do Vale do Araguaia } \\
\text { Faculdade Cathedral de Barra do Garças } \\
\text { Universidade Anhanguera }\end{array}$ & BARRA DO GARÇAS \\
\hline 22 & FID - Faculdade Integradas de Diamantino & DIAMANTINO \\
\hline $\begin{array}{l}23 \\
24 \\
25 \\
26\end{array}$ & $\begin{array}{l}\text { UNEMAT - Universidade de Mato Grosso } \\
\text { UNOPAR (EAD) } \\
\text { FACISA - Faculdade de Ciências Sociais e Aplicadas } \\
\text { FAEL (EAD) - Faculdade Educacional da Lapa }\end{array}$ & CÁCERES \\
\hline $\begin{array}{l}27 \\
28 \\
29 \\
30 \\
31\end{array}$ & $\begin{array}{l}\text { UNEMAT - Universidade de Mato Grosso } \\
\text { UNIC - Universidade de Cuiabá } \\
\text { FASIPE - Faculdade de Sinop } \\
\text { UNISAT (EAD) } \\
\text { UNICESUMAR (EAD) }\end{array}$ & SINOP \\
\hline $\begin{array}{l}32 \\
33\end{array}$ & $\begin{array}{l}\text { FAFLOR - Faculdade de Direito de Alta Floresta } \\
\text { UNOPAR }\end{array}$ & ALTA FLORESTA \\
\hline 34 & UNITEP - Universidade de Ensino Teles Pires & ITAÚBA \\
\hline 35 & AJES - Associação Juinense de Ensino Superior do Vale do Juruena & JUÍNA \\
\hline $\begin{array}{l}36 \\
37\end{array}$ & $\begin{array}{l}\text { UNEMAT - Universidade de Mato Grosso } \\
\text { FITS - Faculdades Integradas de Tangará da Serra - UNIC }\end{array}$ & TANGARÁ DA SERRA \\
\hline $\begin{array}{l}38 \\
39\end{array}$ & $\begin{array}{l}\text { UNICEN - Universidade de Primavera do Leste } \\
\text { UNOPAR (EAD) }\end{array}$ & PRIMAVERA DO LESTE \\
\hline 40 & Faculdade Católica Rainha da Paz & ARAPUTANGA \\
\hline 41 & Faculdade La Salle & LUCAS DO RIO VERDE \\
\hline 42 & UNIC - Universidade de Cuiabá & SORRISO \\
\hline 43 & FCSGN - Faculdade de Ciências Sociais de Guarantá do Norte & GUARANTÁ DO NORTE \\
\hline 44 & $\begin{array}{l}\text { EDUVALE - Faculdade de Ciências Sociais Aplicadas do Vale do São } \\
\text { Lourenço }\end{array}$ & JACIARA \\
\hline 45 & UNOPAR (EAD) & QUERÊNCIA \\
\hline $\begin{array}{l}46 \\
47\end{array}$ & $\begin{array}{l}\text { UNOPAR (EAD) } \\
\text { FACIPEL - Faculdade de Pontes e Lacerda }\end{array}$ & SAPEZAL \\
\hline 48 & UNEMAT - Universidade de Mato Grosso & NOVA MUTUM \\
\hline
\end{tabular}

FONTE: Elaborado pelos autores, 2018

A Coleta de dados iniciou-se analisando as homepages das IES nas matrizes curriculares verificando o uso desta simulação empresarial em alguma disciplina. Como ocorreu a possibilidade destas informaçóes não constarem no site das instituiçóes, foi enviado e-mail 
aos coordenadores e posteriormente, quando foi o caso, houve contato via telefone, até identificar quais IES fazem o uso desta metodologia.

$\mathrm{Na}$ segunda etapa do trabalho avaliou-se com os coordenadores dos cursos de Ciências Contábeis porque seus cursos não utilizam a ferramenta e com os que a utilizam quais vantagens eles identificaram nesta ferramenta. Para coletar estas informaçóes foram utilizados questionários estruturados de autopreenchimento, com questóes fechadas e abertas.

Finalmente, após o processo de coleta, tabularam-se os dados levantados através dos questionários respondidos, a fim de identificar as possíveis contribuiçóes obtidas por meio da aplicação da ferramenta Jogos de Empresas.

\section{ANÁLISE E DISCUSSÃO DOS DADOS}

Para a realização desta pesquisa foram levantados os dados cadastrais das Instituiçôes de Ensino Superior, que estão em regular funcionamento, por intermédio do CRC/MT, com a característica que possuam o curso de Ciências Contábeis. Sendo que o número total de IES no Estado de Mato Grosso são 48, porém, 20 são Educação a Distância, estas, não entraram na amostra, pois não faziam parte do objetivo da pesquisa.

Foram analisados os dados coletados por meio do questionário de pesquisa aplicado. Para uma coleta mais detalhada de informaçóes foram elaborados dois questionários, com o objetivo de responder com maior precisão o problema central da pesquisa, estabelecendo um para as IES que aplicam os Jogos de Empresas, e o outro para as IES que não aplicam esta ferramenta.

\subsection{Perfil das Instituiçóes de Ensino Superior}

Encontram-se um total de 28 IES, instaladas no Estado de Mato Grosso, em dezenove cidades diferentes. Para maior visibilidade, o Quadro 2 mostra a relação das IES que foram abordadas, para contribuir com a pesquisa, respondendo um dos questionários.

Quadro 2 -IES da amostra

\begin{tabular}{|c|l|c|}
\hline $\mathbf{N}^{\circ}$ & IES - MT & CIDADES \\
\hline 1 & UFMT - Universidade Federal De Mato Grosso & \\
2 & UNIRONDON - Centro Universitário Cândido Rondon & CUIABÁ \\
3 & UNIC - Universidade de Cuiabá & \\
4 & ICEC - Instituto Cuiabá de Ensino e Cultura & VÁRZEA GRANDE \\
\hline 5 & UNIVAG - Universidade de Várzea Grande & \multirow{2}{*}{ RONDONÓPOLIS } \\
\hline 6 & UFMT - Universidade Federal De Mato Grosso & \multirow{2}{*}{ BARRA DO GARÇAS } \\
7 & UNIR - Universidade de Rondonópolis & DIAMANTINO \\
\hline 8 & UNIVAR - Faculdade Unida do Vale do Araguaia & \multirow{2}{*}{ CÁCERES } \\
9 & Faculdade Cathedral de Barra do Garças & \\
\hline 10 & FID - Faculdade Integradas de Diamantino & \\
\hline 11 & UNEMAT - Universidade de Mato Grosso & \\
12 & FACISA - Faculdade de Ciências Sociais e Aplicadas & \\
\hline
\end{tabular}




\begin{tabular}{|c|l|c|}
\hline $\mathbf{N}^{\circ}$ & IES - MT & CIDADES \\
\hline 13 & UNEMAT - Universidade de Mato Grosso & SINOP \\
14 & UNIC - Universidade de Cuiabá & \\
15 & FASIPE - Faculdade de Sinop & ALTA FLORESTA \\
\hline 16 & FAFLOR - Faculdade de Direito de Alta Floresta & ITAÚBA \\
\hline 17 & UNITEP - Universidade de Ensino Teles Pires & JUÍNA \\
\hline 18 & AJES - Associaçáo Juinense de Ensino Superior do Vale do Juruena & TANGARÁ DA SERRA \\
\hline 19 & UNEMAT - Universidade de Mato Grosso & PRIMAVERA DO LESTE \\
20 & FITS - Faculdades Integradas de Tangará da Serra - UNIC & ARAPUTANGA \\
\hline 21 & UNICEN - Universidade de Primavera do Leste & LUCAS DO RIO VERDE \\
\hline 22 & Faculdade Católica Rainha da Paz & SORRISO \\
\hline 23 & Faculdade La Salle & GUARANTÃ DO \\
\hline 24 & UNIC - Universidade de Cuiabá & NORTE \\
\hline 25 & FCSGN - Faculdade de Ciências Sociais de Guarantã do Norte & JACIARA \\
\hline 26 & EDUVALE - Faculdade de Ciências Sociais Aplicadas do Vale do Sáo & SAPEZAL \\
\hline 27 & FACIPEL - Pontes e Lacerda & NOVA MUTUM \\
\hline 28 & UNEMAT - Universidade de Mato Grosso & \\
\hline
\end{tabular}

FONTE: Elaborado pelos autores, 2018.

Deste modo, o quadro acima apresenta a amostra inicial de 28 IES que têm curso de Ciências Contábeis, com a característica de presenciais.

Com o auxílio da planilha encaminhada pelo CRC/MT, mencionada resumidamente, no Quadro 1, foi possível entrar em contato com as Instituiçóes com maior facilidade, a princípio. Nesta planilha constam os e-mails e os telefones dos coordenadores do curso de Ciências Contábeis. Em 2017/2, iniciou-se a pesquisa, visitando os websites das Instituiçóes, porém não foi encontrada nenhuma informação sobre Jogos de Empresas nas matrizes curriculares, expostas online. Com isso, encaminharam-se e-mails aos coordenadores dos cursos, mas, ainda assim, não houve respostas de imediato. Em função de nenhum retorno eletrônico, em 2018/1 definiu-se realizar contato telefônico. Somente após iniciar as ligaçóes que se surtiram efeitos positivos, ou seja, informando via telefone sobre o objetivo da pesquisa os coordenadores começaram a responder os e-mails encaminhados pela segunda vez. O resultado do primeiro contato telefônico foi o retorno de quatro (4) Instituiçóes com respostas satisfatórias do questionário. Mas, visando coletar mais respostas, encaminhou-se pela terceira e-mail aos coordenadores, que haviam sidos comunicados via telefone sobre a pesquisa, de vinte, somente dois (2) responderam. Após mais esta tentativa via endereço eletrônico, realizaram-se mais três ligaçóes, em dias alternados, e com isso, atingiu-se mais três (3) IES. Sendo que dois responderam via e-mail e um por telefone. Por fim, um (1) questionário foi respondido pessoalmente. No entanto, ocorreu de onze Instituiçóes não atenderam aos telefonemas, após quatro tentativas telefônicas, e sete mesmo após o contato, via telefone, não se dispuseram responder o questionário. 
Portanto, a análise dos dados foi realizada com os dez questionários de pesquisa recebidos com respostas. No Quadro 3 consta a denominaçáo e as cidades onde está localizada cada Instituição que contribuiu com a pesquisa.

Quadro 3 - IES que responderam um dos questionários de pesquisa

\begin{tabular}{|c|l|c|}
\hline $\mathbf{N}^{\circ}$ & IES - MT & CIDADES \\
\hline 1 & UFMT - Universidade Federal De Mato Grosso & CUIABÁ \\
\hline 2 & UFMT - Universidade Federal De Mato Grosso & RONDONÓPOLIS \\
3 & UNIR - Universidade de Rondonópolis & BARRA DO GARÇAS \\
\hline 4 & UNIVAR - Faculdade Unida do Vale do Araguaia & DIAMANTINO \\
\hline 5 & FID - Faculdade Integradas de Diamantino & ALTA FLORESTA \\
\hline 6 & FAFLOR - Faculdade de Direito de Alta Floresta & TANGARÁ DA SERRA \\
\hline 7 & UNEMAT - Universidade de Mato Grosso & LUCAS DO RIO VERDE \\
8 & FITS - Faculdades Integradas de Tangará da Serra - UNIC & NOVA MUTUM \\
\hline 9 & Faculdade La Salle & \\
\hline 10 & UNEMAT - Universidade de Mato Grosso & \\
\hline
\end{tabular}

FONTE: Elaborado pelos autores, 2018

Estas Instituiçóes citadas são as que realmente apresentam a amostra obtida para o presente trabalho, pois responderam com exatidáo um dos respectivos questionários da pesquisa, retratando a real situação em que se enquadra as IES sobre a ferramenta Jogos de Empresas. Com as informaçôes adquiridas foi possível atender todos os objetivos propostos.

\subsection{Perfil dos Entrevistados}

A pesquisa realizada contou com a participação de dez coordenadores do curso de Ciências Contábeis de algumas Instituiçōes de Ensino Superior do Estado de Mato Grosso.

Entre os dados coletados identificou-se em relação ao sexo dos entrevistados, coordenadores do curso de Ciências Contábeis das IES/MT que 60\% é composto por mulheres e $40 \%$ por homens. Pode-se observar que as mulheres estáo ganhando espaço na coordenação deste curso, sendo maior quantidade em relação aos homens, neste Estado.

Sobre a titulação dos entrevistados da pesquisa, solicitou-se no questionário, saber qual a titulação eles possuem, sendo assim, pode-se observar, a seguir, pela classificação representada na figura. 
Figura 1 - Titulação dos entrevistados

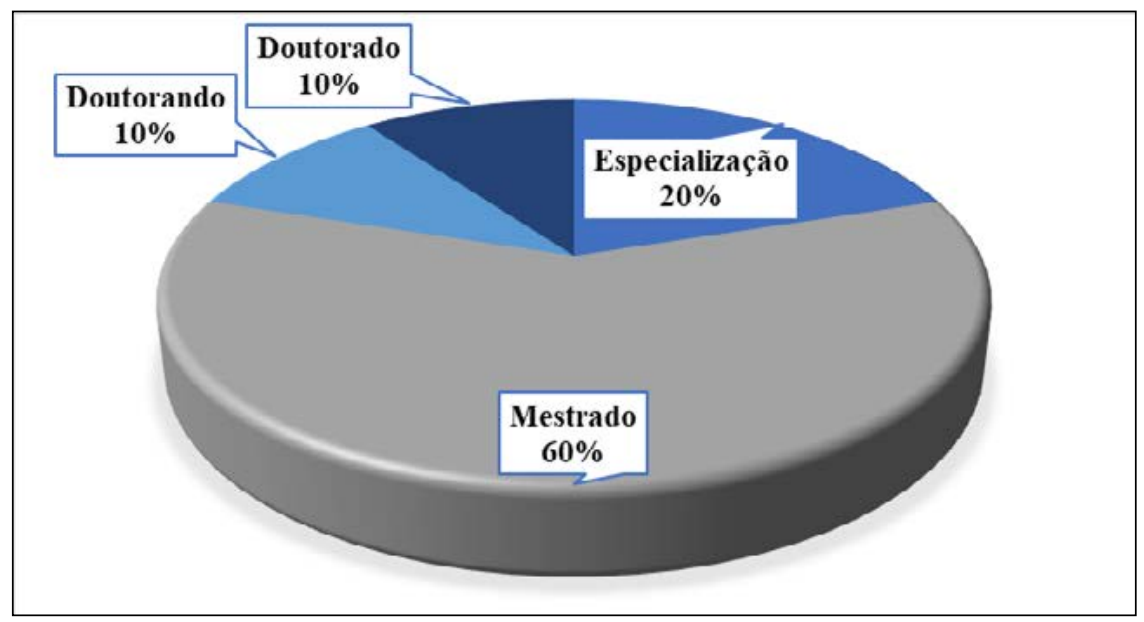

FONTE: Elaborado pelos autores, 2018.

Conforme ilustra a Figura, de 100\% dos entrevistados, há 20\% com o título de Especialista, sendo a maioria os $60 \%$ como Mestre, $10 \%$ em processo de Doutoramento e $10 \%$ titulado como Doutor. Considera-se satisfatório o percentual de Mestres e Doutores/ Doutorandos no curso de Ciências Contábeis, para um Estado, em que os docentes precisam sair do local de origem para se capacitarem, porém se comparar com outras áreas do conhecimento ainda faltam investir em capacitação.

\subsection{Análise e Discussão dos Questionários de Pesquisa}

Este tópico tem como objetivo analisar os dados adquiridos através dos questionários de pesquisa aplicado. A análise está dividida em duas etapas, a primeira retrata a experiência das IES que não utilizam Jogos de Empresas, em suas matrizes curriculares, ea segunda analisa uma IES que relatou utilizar a ferramenta como processo de ensino e de aprendizagem. Para maior entendimento, a análise está seguindo as perguntas realizadas nos questionários de pesquisa.

A princípio, as questōes de número 1 e 2 são similares nos dois questionários, por isso, a tabulação destas questóes foi realizada conjuntamente.

A primeira pergunta teve como finalidade saber como as IES estáo se organizando para executar as atividades em um período letivo. Qual a duraçáo dos cursos de Ciências Contábeis nas respectivas Instituiçôes e ainda se o regime adotado é anual ou semestral. Sendo assim, descreve-se: "Qual a duraçáo do curso de Ciências Contábeis na Instituição? Regime é Anual ou Semestral?” 
Quadro 4 - Duração e Regime dos Cursos de Ciências Contábeis

\begin{tabular}{|l|c|c|}
\hline IES - MT & DURAÇÃO DO CURSO & REGIME ADOTADO \\
\hline Instituição de Ensino Superior A & 4 ANOS & ANUAL \\
\hline Instituição de Ensino Superior B & 5 ANOS & ANUAL \\
\hline Instituição de Ensino Superior C & 4 ANOS & SEMESTRAL \\
\hline Instituição de Ensino Superior D & 4 ANOS & ANUAL \\
\hline Instituição de Ensino Superior E & 4 ANOS & ANUAL \\
\hline Instituição de Ensino Superior F & 4 ANOS & SEMESTRAL \\
\hline Instituição de Ensino Superior G & 4 ANOS & SEMESTRAL \\
\hline Instituição de Ensino Superior H & 4 ANOS & SEMESTRAL \\
\hline Instituição de Ensino Superior I & 4 ANOS & SEMESTRAL \\
\hline Instituição de Ensino Superior J & 4 ANOS & SEMESTRAL \\
\hline
\end{tabular}

FONTE: Elaborado pelos autores, 2018.

Segundo o Quadro 4, de dez Instituições de Ensino Superior, participantes da pesquisa, nove tem como duração do curso 4 anos, e apenas uma com o prazo de 5 anos. Ainda de acordo com a primeira pergunta dos questionários, o regime adotado por cada Instituição é de quatro seguirem o regime anual e seis o regime semestral.

A segunda pergunta realizada nos questionários de pesquisa tinha como objetivo responder quais os turnos utilizados pelas IES para oferta do curso de Ciências Contábeis aos acadêmicos. Diante disso, o quadro a seguir retrata os turnos disponibilizados por cada Instituição.

Quadro 5-Turnos oferecidos pelas IES/MT

\begin{tabular}{|l|c|}
\hline IES - MT & Turnos dos Cursos de Ciências Contábeis \\
\hline Instituição de Ensino Superior A & MATUTINO E NOTURNO \\
\hline Instituição de Ensino Superior B & MATUTINO E NOTURNO \\
\hline Instituição de Ensino Superior C & NOTURNO \\
\hline Instituição de Ensino Superior D & NOTURNO \\
\hline Instituição de Ensino Superior E & NOTURNO \\
\hline Instituição de Ensino Superior F & NOTURNO \\
\hline Instituição de Ensino Superior G & NOTURNO \\
\hline Instituição de Ensino Superior H & NOTURNO \\
\hline Instituição de Ensino Superior I & NOTURNO \\
\hline Instituição de Ensino Superior J & \\
\hline
\end{tabular}

FONTE: Elaborado pelos autores, 2018.

Nota-se no Quadro 5 que todas as IES oferecem o curso de Ciências Contábeis no período noturno, totalizando $100 \%$ da amostra. Porém, duas também disponibilizam o curso no período matutino. 
A pergunta número 3 teve como intuito conhecer quais IES fazem o uso da ferramenta Jogos de Empresas em sua matriz curricular. No questionário para as IES que não utilizam Jogos de Empresas, a pergunta enfatizou se estas faziam o uso da ferramenta há mais de um ano, sendo assim descrita: "A Universidade possui a ferramenta Jogos de Empresas ou Simulaçôes Empresariais há mais de um ano?"

Como houve a resposta negativa de $90 \%$ das Instituiçóes. Apenas 10\% está inserida no outro questionário, elaborado para as IES que fazem o uso desta ferramenta de ensino. A pergunta número 3 deste questionário realizou o seguinte questionamento: "Há quanto tempo utiliza-se Jogos de Empresas na grade curricular da Instituição?"

Uma Instituição de Ensino Superior respondeu que há 13 anos utiliza esta metodologia de ensino-aprendizagem. Sendo assim, o fato de ter esta metodologia em apenas uma IES, já permite responder o problema central desta pesquisa, apesar da amostra ser restrita, o objetivo pode ser atingido, em saber qual a contribuição é oferecida pelos Jogos de Empresas na matriz curricular do curso de Ciências Contábeis desta IES.

As dez Instituições, participantes da pesquisa, receberam ligaçôes antes de responderem os questionários via e-mail, por isso foi possível direcioná-las quais dos dois questionários responderiam. A partir de agora, a análise é sobre o questionário aplicado as IES que não utilizam Jogos de Empresas. Considera-se que de 100\% das IES que responderam 90\% está nesta análise.

A questáo número 4 deste questionário propôs saber se mesmo não havendo a utilizaçáo dos Jogos de Empresas, se os coordenadores tinham conhecimento da ferramenta. Sendo perguntado da seguinte forma: "Você tem conhecimento da ferramenta Jogos de Empresas?” Todos responderam SIM.

Logo, na questão número 5 tinha como objetivo saber se os coordenadores das IES já tinham vivido alguma experiência com os Jogos de Empresas. Realizando a seguinte pergunta: "Já teve alguma experiência com esta ferramenta?"

Das respostas de nove Instituiçóes que participaram deste questionário observou-se que $56 \%$ negaram ter vivido uma experiência com a ferramenta Jogos de Empresas e $44 \%$ afirmaram que já tiveram essa oportunidade.

A finalidade da questão número 6 era justamente saber por que as IES não utilizam Jogos de Empresas como uma metodologia no processo de ensino e de aprendizagem, em sua matriz curricular. Segue na íntegra, como a questão foi elaborada: "Por qual motivo não se utiliza esta ferramenta como método de ensino na matriz curricular da Instituição em que você atua?".

No Quadro 6, estão expostas as opiniōes das noves Instituições que responderam este questionário. 
Quadro 6-Motivos pelos quais não se utilizam Jogos de Empresas

\begin{tabular}{|c|c|}
\hline IES - MT & Respostas obtidas nos Questionários \\
\hline Instituição de Ensino Superior A & Não está previsto no Projeto Pedagógico do Curso. \\
\hline Instituição de Ensino Superior B & $\begin{array}{l}\text { Os professores não utilizam em razão dos custos, pois, normalmente, as } \\
\text { empresas liberam apenas uma turma para teste. }\end{array}$ \\
\hline Instituição de Ensino Superior C & Porque usamos o laboratório com práticas contábeis. \\
\hline Instituição de Ensino Superior D & $\begin{array}{l}\text { Por não ter o programa específico, docente para desenvolver, ou seja, } \\
\text { não há professor habilitado. Mas, há uma gincana, com brincadeiras } \\
\text { que desenvolve o ensino-aprendizado do discente realizado uma vez por } \\
\text { ano. Há também } 120 \mathrm{~h} \text { de estágio aplicado, de forma parecida com os } \\
\text { jogos de empresas. }\end{array}$ \\
\hline Instituição de Ensino Superior E & $\begin{array}{l}\text { Nós trabalhamos com Escritório Junior e com sistemas em Laboratório. } \\
\text { No momento não inserimos na Matriz. Mas gostaria de ter sua ajuda } \\
\text { após resultado desta pesquisa para quem sabe inserir em nosso PPC no } \\
\text { próximo ano. Conto com sua colaboraçấo. }\end{array}$ \\
\hline Instituição de Ensino Superior F & Por não termos contato com a ferramenta. \\
\hline Instituição de Ensino Superior G & $\begin{array}{l}\text { Porque se aplica laboratório de práticas contábeis, esta disciplina } \\
\text { acontece no decorrer de três semestres, onde são realizadas todas as } \\
\text { simulaçóes desde a constituição de empresas, admissáo e demissáo } \\
\text { de funcionários, aquisição de mercadorias, vendas de mercadorias, } \\
\text { fechamento de balanço, declaraçóes. É um laboratório que leva o } \\
\text { acadêmico experimentar de forma simulada a realidade do dia a dia de } \\
\text { uma organizaçáo. }\end{array}$ \\
\hline Instituição de Ensino Superior H & $\begin{array}{l}\text { Estou atuando a pouco tempo na IES e não tive oportunidade de } \\
\text { alteraçáo de PPC. }\end{array}$ \\
\hline Instituição de Ensino Superior I & $\begin{array}{l}\text { Por conta do custo de aquisição não é oferecido, porém está na matriz } \\
\text { como disciplina eletiva. }\end{array}$ \\
\hline
\end{tabular}

FONTE: Elaborado pelos autores, 2018.

Diante do Quadro 6, verificam-se quais são os motivos existentes, para não fazerem o uso da ferramenta Jogos de Empresas, em cada Instituição. É possível constatar que de nove IES que responderam, duas disseram não estar previsto no Projeto Pedagógico do Curso, uma por não ter contato com a ferramenta, outras duas por razão do custo de aquisição e sendo a maioria, quatro, disseram utilizar estágio aplicado, ou mais conhecido como laboratório de práticas contábeis.

Ou seja, apesar de não fazerem o uso dos Jogos de Empresas, em suas matrizes curriculares, algumas IES buscam um processo de ensino e de aprendizagem alternativo em que se propóe a experiência vivencial, assemelhando-se com a vida real.

A questão número 7 procurou instigar os coordenadores do curso, buscando saber qual seria o interesse em desenvolver Jogos de Empresas na IES, em que eles atuam. Segue a pergunta, realizada: "Qual o grau de interesse em implantar este método de ensino no curso em que você atua?” Conforme o Gráfico 2, a seguir, apresenta-se quais as opções foram selecionadas. 
Gráfico 1 - Grau de interesse pela implantação do método Jogos de Empresas

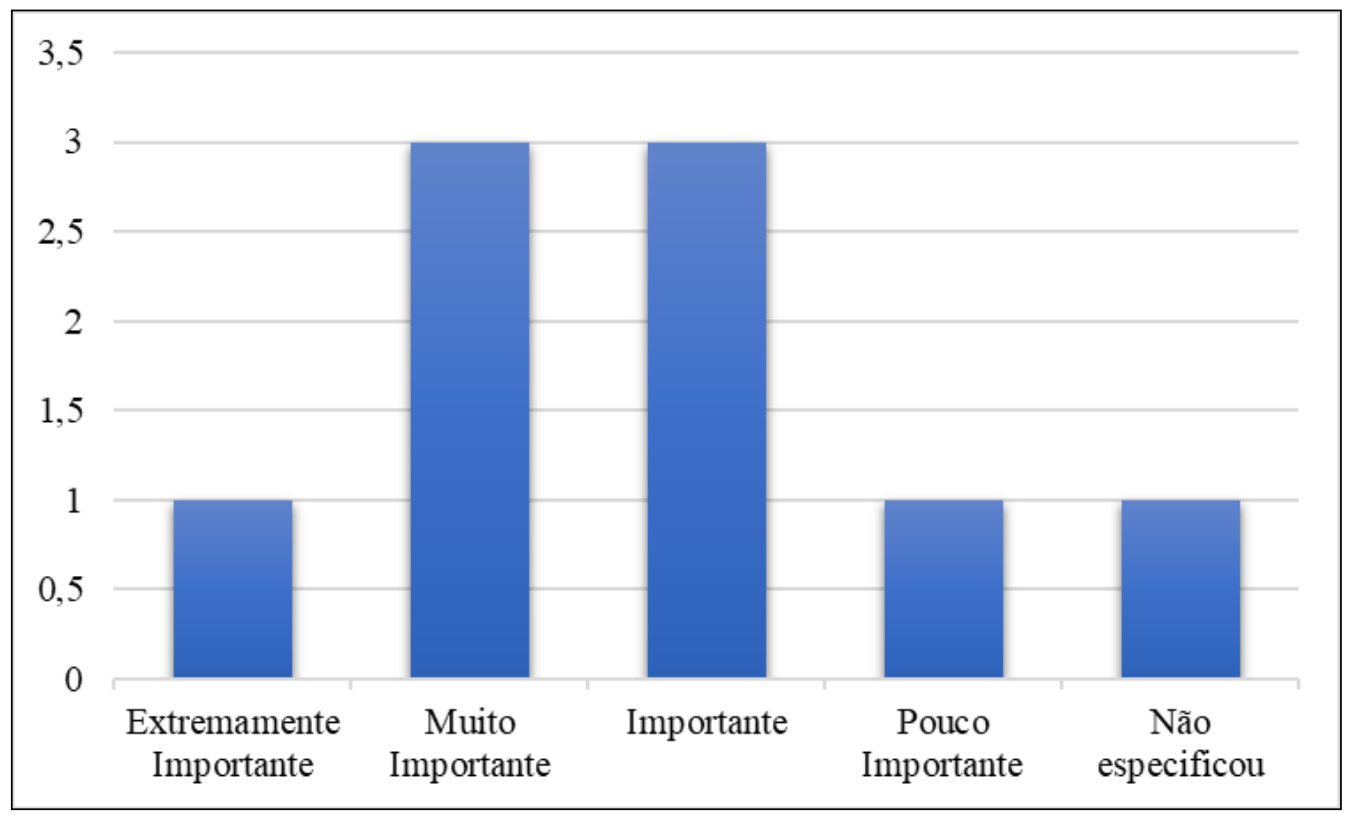

FONTE: Elaborado pelos autores, 2018.

Nota-se, que um coordenador considera extremamente importante implantar o método de ensino Jogos de Empresas na IES em que atua. Três, responderam ser muito importante, e ainda, três disseram ser importante. Uma coordenadora diz ser pouco importante, e uma não especificou qual o grau de interesse em implantar este método.

Finalizando o questionário das IES que não fazem o uso da ferramenta Jogos de Empresas, a última questão, de número 8, teve como interesse saber se as IES têm algum projeto a ser desenvolvido para a implantação deste método. A pergunta foi, assim, realizada: "Existe algum projeto para esta ferramenta entrar em vigor?". Nove IES responderam este questionário, sendo que sete disseram não ter nenhum projeto para esta ferramenta entrar em vigor, e apenas duas, responderam ter um projeto a ser desenvolvido futuramente.

A partir de agora, a análise reflete sobre o questionário aplicado à única IES que utiliza Jogos de Empresas como metodologia no processo de ensino e de aprendizagem.

As questôes iniciais já foram respondidas, juntamente, com o outro questionário, por isso, a questão a seguir é de número 4, com o seguinte questionamento: "Qual Jogo de Empresas utiliza? Foi desenvolvido pela IES ou adquirido?” A coordenadora do curso afirmou utilizar o simulador industrial: Bernard Simulação Gerencial.

A questáo número 5 responde à pergunta da pesquisa que destaca a vantagem em fazer o uso da ferramenta no processo de ensino e de aprendizagem. A pergunta realizada no questionário segue assim, descrita: "Qual a contribuição que a ferramenta Jogos de Empresas oferece ao ensino-aprendizagem do curso de graduação de Ciências Contábeis em sua opiniáo?”. 
A resposta obtida segue na íntegra: "Esta ferramenta permite que o acadêmico se aproxime um pouco, ainda que em ambiente simulado da prática empresarial, sob a ótica do tomador de decisão. Ao analisar dados e tomar decisóes o acadêmico desenvolve a capacidade de interpretar as informaçôes contábeis e de pensar e agir estrategicamente".

Ou seja, há uma contribuição positiva, com a utilização desta ferramenta, na matriz curricular, do curso de Ciências Contábeis desta IES. Como descrito pela coordenadora, este simulador, permite que os discentes tenham experiências simuladas em um ambiente virtual, no entanto, desta forma podem tomar decisões estratégicas com base nos conhecimentos adquiridos ao longo do curso. Com isso, os discentes podem ingressar no mercado de trabalho com uma vivência mais aprofundada sobre a realidade, afinal o processo de ensino e de aprendizagem explorou o campo prático dentro da IES.

A questáo número 6 deste questionário, foi dividida em quatro perguntas, tendo como objetivo saber sobre o docente que ministra a disciplina, realizadas, da seguinte forma: "Qual a titulação do docente que ministra a disciplina e área de formação? Quantos anos atua como professor? Quantos anos na aplicação de Jogos de Empresas? Qual o objetivo da aplicaçáo dos Jogos de Empresas?". A coordenadora do curso respondeu: "O docente é contador, com mestrado em saúde coletiva e doutorado em Ciências da Saúde. Atua como professor há 16 anos e está na aplicação dos Jogos de Empresas há dois anos e que se trata de uma Disciplina específica”.

Nota-se que o objetivo dos Jogos de Empresas é ter uma disciplina voltada somente para este campo no processo de ensino e de aprendizagem. Sendo assim, está prevista na matriz curricular do curso de Ciências Contábeis, da IES respondente.

A questáo número 7 propôs saber onde é aplicado os Jogos de Empresas, seguindo com a pergunta: "O ambiente onde é aplicado o Jogo é no laboratório, sala de aula, ambos ou outro?" Obteve-se como resposta, esta afirmação: "Em virtude de se trabalhar com sistema on-line as atividades são realizadas no laboratório de informática".

A questão número 8 teve como objetivo saber se a IES continuará com o método Jogos de Empresas, na matriz curricular, realizando a pergunta: "A IES pretende continuar utilizando?" Como resposta da participante, obteve-se: "Sim".

Nota-se com as respostas das questôes 7 e 8 , que como o sistema utilizado, pela IES, dos Jogos de Empresas é on-line, os discentes vivenciam esta experiência na própria Instituição, em um laboratório específico para esta disciplina. A IES afirmou que vai dar continuidade na utilização deste método de ensino, acredita-se, que um dos motivos seja pela resposta obtida deles da satisfação dos discentes com a metodologia.

Já, a questão 9, teve como finalidade conhecer o ponto de vista da coordenadora, em relação a importância em utilizar esta ferramenta na matriz curricular do curso de Ciências Contábeis. A questão foi assim descrita: "Qual o grau de importância que você atribui à utilização dos Jogos de empresas como metodologia de ensino?” No questionário recebido, a coordenadora, optou em responder: "Extremamente importante".

Para finalizar as análises em relação ao questionário da IES que utiliza Jogos de Empresas, como ferramenta no processo de ensino e de aprendizagem, abordou-se na questáo número 10 saber qual a opiniáo da coordenadora, sobre a satisfaçáo dos discentes 
que participam da experiência de trabalhar em sala de aula com esta metodologia. A pergunta foi realizada da seguinte forma: "Em sua opiniáo qual o grau de satisfação dos discentes com a utilização da ferramenta?". Como a questáo é fechada, a coordenadora marcou como resposta: "Muito satisfeitos". Ou seja, os discentes, os quais vivenciam a experiência dos Jogos de Empresas, apresentam um desenvolvimento satisfatório em poder participar desta vivência como método no processo de ensino e de aprendizagem.

Diante das respostas obtidas, observa-se que sendo apenas uma IES a utilizar a ferramenta Jogos de Empresas, ainda destaca-se que são poucas as Instituições que tem interesse em implantar esta metodologia, preferindo investir em outros métodos de ensino. Com isso, a amostra é pequena para saber qual a contribuição proporcionada aos discentes através dos Jogos de Empresas, em uma matriz curricular, para o curso de Ciências Contábeis. Porém é válido ressaltar que uma Instituição respondeu ter interesse no resultado final desta pesquisa, para que futuramente possa implantar esta ferramenta, na matriz curricular da Instituição.

\section{CONSIDERAÇÓES FINAIS}

O presente estudo almejou pesquisar quais IES fazem o uso da ferramenta Jogos de Empresas, e quais as contribuiçôes adquiridas através deste método de ensino, supostamente tecnológico e inovador em sala de aula. Em meio as principais questóes abordadas destacamse que dentre todas as Instituiçóes participantes da pesquisa, somente uma possui Jogos de Empresas, na matriz curricular do curso de Ciências Contábeis, no Estado de Mato Grosso.

Obtiveram-se junto aos coordenadores das IES, que não fazem o uso da ferramenta Jogos de Empresas, os motivos que os levam a náo utilizar esta metodologia. Observouse que os principais motivos elencados foram: falta de contato com a ferramenta, pela dificuldade no custo aquisição, por não estar previsto no PPC, e, de modo geral, por já fazer o uso do estágio aplicado, o qual se assemelha aos Jogos de Empresas.

A IES que possui Jogos de Empresas na matriz curricular destacou a vantagem em fazer o uso da ferramenta, como um desenvolver de capacidade ao aproximar o acadêmico da prática empresarial, possibilitando o desempenho estratégico ao ter a necessidade da tomada de decisão em tempo real.

Também, foi solicitado no questionário sobre o perfil do docente que ministra a disciplina específica Jogos de Empresas. Quanto a isso, a coordenadora descreveu qual a titulação que o docente possui, quanto tempo atua como professor e há quantos anos está utilizando a ferramenta. Percebe-se com a resposta obtida sobre o docente, que o mesmo não está na área de sua especialização. No entanto, atua como orientador desta disciplina.

Diante de todas as questões, confirma-se que poucas são as IES do Estado de Mato Grosso que possuem Jogos de Empresas em suas matrizes curriculares, assim, a metodologia utilizada atualmente não tem recebido as contribuiçôes da ferramenta educacional, a qual permitiria que os acadêmicos vivenciassem o mundo real, através de simulações empresariais virtualmente. Considera-se que em função dos benefícios que esta ferramenta traz aos discentes, conforme identificado no referencial teórico, outras IES deveriam implantar este método de ensino. 


\section{REFERÊNCIAS}

ALMEIDA, Fernando C. de. Experiências no uso de jogos de empresas no ensino de Administração. Anais do III SemeAd FEA/USP, 1998.

ARRUDA, Elenir Cristina A. Lista das Instituiçóes de Ensino Superior [mensagem pessoal]. Mensagem recebida por <assessoria1@crcmt.org.br>. em 15 jul. 2017.

BEUREN, Ilse Maria et al. Como elaborar trabalho monográficos em contabilidade: teoria e prática. 3. ed., 5. reimpr., São Paulo: Atlas, 2010.

BRASIL. CNE/CES 10 - Lei das Diretrizes Curriculares Nacionais para o Curso de Graduaçáo em Ciências Contábeis. Brasília, DF, 2004.

FAGHERAZZI, M. A. ; RIBEIRO, A. M. ; BUENO, V. F. ; RAMOS, B. M. ; SILVA, M. A. ; VIRGILIO, M. P. ; ZWIEREWICZ, M. . Mediação didática em espaços presenciais e virtuais de aprendizagem. In: ENDIPE, 12. - Encontro Nacional de Didática e Prática de Ensino, 2004, Curitiba. Conhecimento local e conhecimento universal, 2004. v. 1.

FREIRE, Paulo. Pedagogia da autonomia - saberes necessários à prática educativa. São Paulo: Paz e Terra, 2003.

GIL, Antônio Carlos. Como elaborar projetos de pesquisa. 4 ed., São Paulo: Atlas, 2008.

GRACIA, A. L. C. Benefícios e dificuldades na utilização dos jogos de empresas: survey em cursos de graduação em administração na região noroeste do estado de São Paulo, 2014. 74p. Dissertação (Mestrado em Engenharia da Produção) - Universidade Estadual Paulista, Bauru, 2014.

GUBERT, Raphaela Lupion; MACHADO, Mércia Freire Rocha Cordeiro. A prática docente e o novo paradigma educacional virtual. In: Congresso Nacional de Educação, 9 - EDUCERE. In: Encontro Sul Brasileiro de Psicopedagogia, 3. 26 a 29 de out. 2009. Anais Eletrônicos... Curitiba: PUCPR, 2009. Disponível em: <http://educere.bruc.com. br/arquivo/pdf2009/3418_1822.pdf>. Acesso em: 15 jun. 2017.

KALLÁS, David. A utilização de jogos de empresas no Ensino da administraçáo. Disponível no site: <http://br.monografias.com/trabalhos/utilizacao-jogos-empresasensino-administracao/utilizacao-jogos-empresas-ensino-administracao.shtml>. Acesso em: 15 ago. 2017.

KEYS, J.B.; WOLFE, Joseph. The Role of Management Games and Simulations for Education and Research. Journal of Management, v. 16, n. 2, p. 307-336, 1990. 
LAFFIN, Marcos. De contador a professor: a trajetória da docência no ensino superior de contabilidade. 2002. 191f. Tese de Doutorado em Engenharia de Produção. Universidade Federal de Santa Catarina, UFSC, 2002.

LIMA, T. B.; SILVA, A. B. Difusão das Estratégias de Ensino balizadas pela Aprendizagem em ação no Curso de Administração. In: ENCONTRO DA ANPAD - ANPAD, 36, 2012, Rio de Janeiro. Anais... Rio de Janeiro: ANPAD, 2012.

LOBO, A. S. M.; MAIA, L. C. G. O uso das TICs como ferramenta de ensinoaprendizagem no Ensino Superior. Caderno de Geografia, Belo Horizonte, v. 25, n. 44, p. 16-26, mai., 2015. Disponível em: <http://200.229.32.55/index.php/geografia/article/ view/P.23182962.2015v25n44p16/8055>. Acesso em 15 ago. 2017.

LOPES, Maurício Capobianco; WILHELM, Pedro Paulo Hugo. Uso de jogos de simulação empresarial como ferramenta educacional: uma análise metodológica. In: WORKSHOP EM INFORMÁTICA E APRENDIZAGEM ORGANIZACIONAL - WIAO, 1, 2006, Brasília. Anais do XVII SIMPÓSIO BRASILEIRO DE INFORMÁTICA NA EDUCAÇÃO - SBIE. Brasília: UCB, 2006. Disponível em: <http://www.virtual.ufc.br/solar/aula_link/lquim/I_a_P/Psicologia_educacao_II/aula_037754/imagens/02/Jogos\%20e\%20simula\%C3\%A7\%C3\%A3o.pdf>. Acesso em: 15 ago. 2017.

LOPES, M. C. ; FIALHO, F. A. P. ; CUNHA, C. J. C. A. ; NIVEIROS, S. I. . Business Games for Leadership Development: A Systematic Review. Simulation \& Gaming, v. 1, p. 1-21, 2013.

MARCONI, Marina de Andrade; LAKATOS, Eva Maria. Metodologia do trabalho científico: procedimentos básicos, pesquisa bibliográfica, projeto e relatório publicaçóes e trabalhos científicos. 6. ed. São Paulo: Atlas, 2001.

MARION, José Carlos; MARION, Arnaldo Luís Costa. Metodologias de ensino na área de negócios. Para cursos de administração, gestão, contabilidade e MBA. São Paulo: Atlas, 2006.

PARISOTTO, Iara Regina dos Santos; GRANDE, Jefferson Fernando; FERNANDES, Francisco Carlos. O processo de ensino e aprendizagem na formação do profissional contábil: uma visão acadêmica. In: Congresso USP - Iniciação científica em contabilidade. 3., 2006. São Paulo. Anais... São Paulo: USP, 2006. Disponível em: <https://congressousp.fipecafi.org/anais/artigos32006/422.pdf>. Acesso em: 23 jul. 2017.

MARION, José Carlos; GARCIA, Elias; CORDEIRO, Moroni. A discussão sobre a metodologia de ensino aplicável a contabilidade. Disponível em: Acesso em: 23 jul. 2017. 
ROLLO, Lúcia Fransolin; PEREIRA, Anísio Cândido. Análise do processo educacional contábil sob o prisma de seus elementos de maior relevância. Revista Brasileira de Contabilidade, Brasília, n.142, p.49-57, 2003.

SANTOS, Roberto Vatan dos. "Jogos de empresas" aplicados ao processo de ensino e aprendizagem de contabilidade. Revista de Contabilidade e Finanças - USP, São Paulo, n. 31, p. $78-95$, janeiro/abril 2003.

SAUAIA, Antonio C. A. Satisfaçáo e Aprendizagem em Jogos de Empresas:

Contribuições para a Educação Gerencial. 1995, 273 f. Tese (Doutorado) FEA-USP, São Paulo, 1995.

SAUAIA, Antônio Carlos A. Conhecimento Versus Desempenho das Organizações: Um Estudo Empírico com Jogos de Empresas. In: Revista de Administração, v.12, n.1, edição 49, São Paulo: jan-fev 2006.

SCARELLI, A. Mediação do processo ensino-aprendizagem com o jogo de empresas mercado virtual: uma pesquisa de opinião, 2009, 174f. Dissertação (Mestrado em Engenharia da Produção) - Faculdade de Engenharia, Universidade Estadual Paulista, Bauru, 2009.

SOARES, M. L. de A.; NOGUEIRA, E. J.; PETARNELLA, L. Juventude, Gadgets e Educação: reflexôes contemporâneas. Revista Série-Estudos, Campo Grande, n. 38, p. 47-57, jul./dez., 2014.

YOUSSEF, Youssef Ahmad; RAMIREZ, Alejandro. Social software in higher education: pedagogical models and universities strategies. 21. ed. Palhoça, Santa Catarina: Unisul, 2011.

ZAMBELO, E. A. O Uso de jogos de empresas no ensino superior: um estudo sobre a prática docente, 2011, 149s. Dissertação (Mestrado em Administração) - Universidade Estadual Paulista, Faculdade de Engenharia, Bauru, 2011. 